\title{
Editorial: Geosynthetics for Development of Transportation Infrastructures
}

\author{
Sujit Kumar Dash ${ }^{1 *}$ and Castorina Silva Vieira ${ }^{2}$ \\ ${ }^{1}$ Department of Civil Engineering, Indian Institute of Technology Kharagpur, Kharagpur, India, ${ }^{2}$ CONSTRUCT, Faculty of \\ Engineering, University of Porto, Porto, Portugal
}

Keywords: geotechnical engineering, soil improvement, geosynthetics, transportation infrastructures, road, railway

Editorial on the Research Topic

Geosynthetics for Development of Transportation Infrastructures

\section{BACKGROUND}

Present days, several countries across the globe are making large investments in building transportation infrastructures such as highways, railways, airport runways etc. Due to scarcity of land, many times, these structures are being built over weak soils leading to design, construction and maintenance hazards. Geosynthetics in form of geogrids, geotextiles, and geocells, are being widely used to mitigate such problems. Owing to cost economy and ease of construction the reinforced soil technology finds favour with the practicing engineers. Contributions serving this special issue cover a range of topics, from evaluation of material properties, physical modelling, and numerical modelling,

OPEN ACCESS

Edited and reviewed by: Sakdirat Kaewunruen, University of Birmingham, United Kingdom

${ }^{*}$ Correspondence: Sujit Kumar Dash suji@civil.itkgp.ac.in

Specialty section: This article was submitted to Transportation and Transit Systems, a section of the journal Frontiers in Built Environment

Received: 20 January 2021 Accepted: 02 February 2021 Published: 17 March 2021

Citation:

Dash SK and Vieira CS (2021) Editorial: Geosynthetics for Development of Transportation Infrastructures. Front. Built Environ. 7:656498. doi: 10.3389/fbuil.2021.656498 to reliability and sustainability analyses of reinforced soils relevant to transportation infrastructures.

\section{HIGHLIGHTS OF CONTRIBUTIONS}

Marques and Lins da Silva have evaluated the confined stiffness of a non-woven geotextile under different molding conditions in a lateritic soil mass, using monotonic pullout tests. It is observed that the geotextile stiffness is significantly influenced by the matrix suction and the grain size structure at its interface with the soil mass. Even under small vertical pressures, the apparent confined stiffness improves considerably compared to the unconfined stiffness which indicates that the use of the unconfined stiffness obtained by index tests may be a conservative measure in paving projects.

Through large-scale pullout tests, Ferreira et al. have observed that soil density is a key parameter for the pullout behaviour of geosynthetics reinforcements. Apart from ultimate pullout resistance it has great influence on the failure mode of the reinforcement, i.e., pullout or tensile rupture. The moisture condition too influences the pullout capacity of geosynthetics, particularly when the soil is in medium dense state. As reinforced soil embankments for railways and highways are compacted at different density and moisture conditions these observations are of significant importance.

Bhatra and Maheshwari have modelled the behaviour of rail tracks on stone column-geocell composite earth beds. To understand the influence of spacing, diameter and stiffness of stone columns on response of the system parametric studies and sensitivity analyses have been carried out. The impact of other relevant parameters such as the applied load and its velocity, the stiffness of top and bottom soil layers, the relative flexural rigidity and depth of placement of geocell has also been considered in this study. The sensitivity analyses of the rail deflection have shown that the maximum upward 
deflection of top beam is not very sensitive toward variation of the relative compressibility of the soil and relative stiffness of the stone column, but exceptionally sensitive to all the other above mentioned parameters.

Hussaini and Sweta have studied the shear behaviour of geogrid-reinforced ballast-sub-ballast interface and the deformation and degradation behaviour of geogrid-reinforced ballast in railway tracks under the cyclic loading conditions. The direct shear tests results have shown that the inclusion of geogrids enhances the shear strength of ballast-sub-ballast interface and decreases the Marsal's breakage index (an index to quantify the breakage of ballast). The results of cubical triaxial tests have also revealed that the inclusion of geogrids reduces the extent of lateral displacement and vertical settlement of ballast.

Through model tests and numerical analyses Dash et al. have investigated the influence of geocell reinforcement on the performance of foundation beds. It is observed that with provision of geocell reinforcement the contact pressure on the subgrade soil reduces significantly, leading to increased bearing capacity of the foundation bed. The numerical analyses have shown that the geocells right under the footing directly sustain the surcharge loading through mobilization of their compressive stiffness and bending rigidity, whereas the end portions of the geocell mattress contribute to the performance improvement through mobilization of anchorage, derived from soil passive resistance and friction.

The experimental and numerical work reported by Hegde and Palsule has highlighted the efficacy of planar and threedimensional geosynthetic reinforcements in improving the performance of subgrade under dynamic loads. The estimated parameters illustrated the three-fold reduction in settlement of the subgrade in the presence of reinforcement. The threedimensional geocell reinforcement performed effectively as compared to planar geogrids under dynamic load.

Existing flexible pavement design procedures based on Layer Coefficient Ratio (LCR) and Traffic Benefit Ratio (TBR) values have been extended to the design of geogrid-reinforced flexible pavements by Goud et al. This study has shown that the geogrid reinforcement can reduce the thickness of granular base and subbase layers by at least $10-45 \%$ for subgrades with $\mathrm{CBR}<5 \%$, and the thickness of the bituminous layer by at least $7 \%$. A reduction of the embodied carbon generated by the construction in the range of $58-85 \mathrm{tCO}_{2} \mathrm{e} / \mathrm{km}$ has also been reported for geogrid-reinforced pavements in comparison with unreinforced pavements.

Reinforced soil structures are often affected by uncertainties related to material properties. Through reliability analysis, Belo and Lins da Silva have studied the influence of such uncertainties in the stability of reinforced soil embankments. The results obtained can be of use in the design and construction of railways and highways on embankments.

Choudhuri and Chakraborty have studied the influence of spatial variability of soil properties on the probabilistic bearing capacity of roadway pavement supported on fibre reinforced earth embankment. The importance of considering spatial variability of the soil shear strength and that of the out of plane length of the embankment are among the main conclusions of their study.

\section{SUMMARY}

The findings of the studies presented in this issue open up new horizons for application of reinforced geosynthetics in design and construction of transportation infrastructures, worldwide. We, editors, hope that the readers will find these contributions valuable.

\section{AUTHOR CONTRIBUTIONS}

All authors listed have made a substantial, direct, and intellectual contribution to the work and approved it for publication.

Conflict of Interest: The authors declare that the research was conducted in the absence of any commercial or financial relationships that could be construed as a potential conflict of interest.

Copyright (C) 2021 Dash and Vieira. This is an open-access article distributed under the terms of the Creative Commons Attribution License (CC BY). The use, distribution or reproduction in other forums is permitted, provided the original author(s) and the copyright owner(s) are credited and that the original publication in this journal is cited, in accordance with accepted academic practice. No use, distribution or reproduction is permitted which does not comply with these terms. 